\title{
Analisis kesesuaian lahan rawa untuk pengembangan kawasan permukiman di Kecamatan Gondang Kabupaten Tulungagung
}

\author{
Anita Eka Putri*, Dwiyono Hari Utomo**, Revi Mainaki* \\ * Jurusan Pendidikan Geografi, Fakultas Keguruan dan Ilmu Pendidikan Universitas \\ Siliwangi, Indonesia \\ ** Jurusan Pendidikan Geografi, Fakultas Ilmu Sosial Universitas Negeri Malang, \\ Indonesia
}

\section{ARTICLES INFO}

Profil Articles:

Sent: 19-2-2019

Approved: 24-6-2019

Published: 30-6-2020

Key words:

kesesuaian lahan, permukiman

\section{Correspondent Author:}

Anita Eka Putri

Pendidikan Geografi

Universitas Siliwangi

Jl Siliwangi No. 24 Tasikmalaya 46115

E-mail: anita.eka@unsil.ac.id

Gondang District is a drained swamp with an area of $37.85 \mathrm{Km}^{2}$ with a slope of $<2 \%$ which is had different physical condition from other settlement areas. This study aimed to evaluate land suitability for settlement development within study area. The data related to slope, soil structure, soil texture, drainage, and depth of ground water level, rock weathering level, level of flooding / flooding, soil carrying capacity, permeability, and potential for soil wrinkle (index cole) were collected through observation. Land unit maps as a unit analyzed resulted from overlay maps of slope, land use maps, and maps of soil types. The results showed that the land which has been developed into a settlement area has some limiting values, hence it is required evaluation when used as a settlement area.

Kecamatan Gondang mempunyai luas area $37,85 \mathrm{Km}^{2}$ dengan kemiringan lereng $<2 \%$ merupakan rawa yang mengalami pengeringan sehingga memiliki kondisi fisik yang berbeda dari kawasan permukiman yang lain. Tujuan penelitian ini untuk melakukan evaluasi kesesuaian lahan untuk pengembangan permukiman di daerah tersebut. Penelitian ini menggunakan metode deskriptif evaluatif. Data kemiringan lereng, struktur tanah, tekstur tanah, drainase, kedalaman muka air tanah, tingkat pelapukan batuan, tingkat penggenangan/banjir, daya dukung tanah, permeabilitas, dan potensi kembang kerut tanah (index cole)dikumpulkan dengan observasi. Peta unit lahan sebagai unit analisis dihasilkan dari overlay peta kemiringan lereng, peta penggunaan lahan, dan peta jenis tanah. Hasil penelitian menunjukkan bahwa lahan yang telah dikembangkan mempunyai beberapa nilai pembatas sehingga perlu adanya evaluasi untuk bisa digunakan sebagai kawasan permukiman .

This is an open access article under the CC-BY-SA license

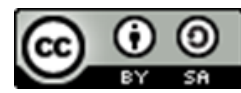


Jurnal Pendidikan Geografi:

Kajian, Teori, dan Praktik dalam Bidang Pendidikan dan Ilmu Geografi

Volume 25, Nomor 2, Jun 2020, Hal 170-178

\section{PENDAHULUAN}

Masalah permukiman mempunyai peranan yang sangat penting dalam pembangunan di Indonesia. Undang-Undang Nomor 11 Tahun 2011 menjelaskan bahwa permukiman merupakan bagian dari lingkungan hunian yang terdiri dari lebih dari satu hunian, terdapat saran dan prasarana, fasilitas umum, dan mempunyai fasilitas penunjang lain (Hilmansyah \& Rudianto, 2015). Pembangunan permukiman harus dilakukan secara terarah dan terencana dengan memperhatikan peningkatan jumlah penduduk dan tata guna lahan sehingga bisa kualitas lingkungan yang baik di daerah perkotaan maupun di pedesaan. Penggunaan lahan sering kali mengabaikan lingkungan sehingga mengakibatkan menurunnya daya dukung lahan (Veni, 2016). Pertimbangan aspek fisik sangat diperlukan karena setiap lahan memiliki kemampuan dan kapasitas lahan yang terbatas (Asmirawati, 2015).

Permukiman menjadi kebutuhan dasar manusia yang tidak lepas dari permasalahan. Peningkatan kebutuhan lahan permukiman sebanding dengan peningkatan jumlah penduduk yang ada (Permana, Suprayogi, \& Prasetyo, 2017). Jumlah penduduk yang terus meningkat memerlukan banyak ruang untuk berbagai fasilitas penunjang seperti lahan permukiman yang memungkinkan terjadinya perubahan penggunaan lahan (Hartono, Anggoro, \& Buchori, 2015). Terjadinya perubahan lahan yang secara terus menerus menyebabkan ketidak sesuaian terhadap tata ruang suatu wilayah. Kawasan permukiman harus mempertimbangkan aspek keruangan sehingga dapat menghasilkan kualitas bangunan yang baik, mempunyai nilai ekonomis tinggi dan menghindar dari dampak lingkungan yang kurang baik. Perencanaan penggunaan lahan yang baik akan berperan pada pembangunan berkelanjutan (Van Lier 1998; Chao et al. 2012) dalam (Ulah \& Mansourian, 2015). Penggunaan lahan untuk permukiman yang tidak sesuai dengan tata ruang dapat menimbulkan permukiman berada pada zona yang kurang nyaman dan dapat menimbulkan berbagai masalah (Hartono, Anggoro, \& Buchori, 2015). Kenyataannya, seringkali masyarakat ataupun para pengembang perumahan (developer) kurang memperhatikan aspek fisik dan lebih mementingkan aspek ekonomi. Hal ini dapat mengakibatkan pemanfaatan lahan tidak optimal berdampak pada lingkungan dan kualitas bangunan yang kurang layak ditinggali (Putra \& Papilaya , 2019). Oleh karena itu perlu adanya pengetahuan tentang kesesuaian lahan khususnya untuk perkembangan permukiman (Mufarikah \& Murti, 2015).

Kecamatan Gondang secara geografis berada di bagian selatan Kabupaten Tulungagung, bagian utara berbatasan dengan Kecamatan Kauman, bagian selatan berbatasan dengan Kecamatan Pakel, bagian barat berbatasan dengan Kabupaten Trenggalek sertabagian timur berbatasan dengan Kecamatan Tulungagung dan Boyolangu. Luas wilayah $37,85 \mathrm{Km}^{2}$ dengan morfologi dataran rendah. Jenis pemanfaatan lahan di daerah tersebut adalah sawah dan tanah kering yang sebagian telah ataupun sedang dibagun permukiman oleh pihak pengembang (developer). Kondisi strategis Kecamatan Gondang didukung oleh kondisi aksesibilitas yang baik, juga relatif dekat dengan pusat kota, membuat wilayah ini mempunyai nilai jual yang terus mengalami peningkatan setiap tahunnya membuat kawasan ini menjadi incaran bagi para pengembang (developer) untuk dijadikan sebagai kawasan permukiman.

Dari sudut pandang morfologi kawasan ini merupakan daerah bekas rawa (marsh). Proses pembentukan rawa dimulai dengan adanya danau atau genangan dangkal yang secara perlahan ditumbuhi tanaman air beserta vegetasi lahan basah yang kemudian mengalami proses timbunan sehingga terjadi dekomposisi anaerob sehingga membuat biota pengurai menjadi rendah. (Yunus, 2014) menjelaskan bahwa "tebal genangan air rawa berflukstuasi menurut pergantian musim hujan dan kemarau”. 
Jurnal Pendidikan Geografi:

Kajian, Teori, dan Praktik dalam Bidang Pendidikan dan Ilmu Geografi

Volume 25, Nomor 2, Jun 2020, Hal 170-178

Kecamatan Gondang terdiri 20 Desa/Kelurahan, 104 Rukun Warga (RW), dan 377 Rukun Tetangga (RT) dengan penggunaan lahan permukiman, perkebunan, sawah, tegal/ladang, semak,sawah, lading (Bappekab, Kabupaten Tulungagung Dalam Angka, 2019). Semak merupakan penggunaan lahan yang dominan mencapai $60 \%$ atau 4.402.000 Ha dari keseluruhan luas wilayahnya sendiri (Bappekab, Rencana Tata Ruang Wilayah Kabupaten Tulungagung 2009-2030, 2010). Daerah tersebut akan dikembangkan sebagai area permukiman, layaknya areal bekas rawa daerah tersebut memiliki karakteristik keterbatasan diantaranya adalah sulit menyerap air sehingga rentan akan terjadi banjir dan sering terjadi limpasan air menyebabkan ketidaknyamanan.

Pemilihan lokasi permukiman yang tepat mempunyai arti penting dalam berbagai aspek keruangan karena akan menentukan keawetan bangunan, mempunyai nilai ekonomis dan mempertimbangkan dampak terhadap lingkungan (Umar, Widiatmaka, Pramudya, \& Barus, 2017). Lokasi sangat berpengaruh terhadap daya dukung tanah berdampak langsung pada pendirian pondasi bangunan dan tingkat keawetan bangunan. Tanah yang memiliki daya dukung yang rendah dapat mengakibatkan tembok yang mudah retak, bangunan mengalami ambles, dan menimbulkan banyak kerugian lain sehingga perlu adanya kajian kesesuaian lahan bekas rawa kawasan permukiman daerah tersebut. Hasil dari kajian kesesuaian lahan dapat dijadikan sebagai dasar dalam perumusan kebijakan pemerintah dalam mengembangkan kawasan permukiman di Kabupaten Tulungagung khususnya di wilayah kecamatan Gondang (Susetya, Widyatmaka, \& Arifin, 2014).

\section{METODE}

Penelitian ini menggunakan metode deskriptif evaluatif untuk menganalisa dan menginterpretasi karakteristik lahan yang akan dijadikan penentukan lokasi permukiman. Data yang diperlukan ada dua jenis yakni data primer dan data sekunder. Data primer diperoleh dari hasil survey meliputi kemiringan lereng, potensi air tanah, drainase, tingkat pelapukan batuan, tekstur tanah, struktur tanah, permeabilitas, tanah dan potensi kembang kerut tanah (index cole).Data sekunder diperoleh dari hasil wawancara kepada penduduk setempat untuk mengetahui tingkat intensitas penggenangan/banjir.

Kedua data dianalisis dengan dideskripsikan guna memberikan penjelasan secara sistematis, karakteristik lahan bekas rawa di lokasi tersebut kemudian dilakukan evaluasi dengan mengkatogorikannya dalam karakteristik kelas kesesuaian lahan untuk kawasan permukiman. Pengambilan data dilakukan melalui penentuan sampel penelitian dengan purposive sampling hasil overlay 3 peta, yakni peta kemiringan lereng, peta jenis tanah dan peta penggunaan lahan. Dari overlay tersebut menghasilkan penentuan titik pengambilan sampel dengan skala 1: 60.000 pada Gambar 1 dan untuk penentuan titik sampel pada Tabel 1 .

Dari sampel yang telah diambil kemudian dilakukan pengharkatan dan skoring untuk menentukan karakteristik lahan untuk memberikan nilai pada masing-masing karakteristik lahan dalam satuan unit lahan sehingga dapat diklasifikasikan dalam kriteria kelas kesesuaian lahan sebagai kawasan permukiman. Untuk memperkuat data penelitian juga dilakukan uji laboratorim, dan pengukuran lapangan.

\section{HASIL DAN PEMBAHASAN}

Wilayah Kecamatan Gondang terletak pada koordinat $111^{\circ} 50^{\prime} 49^{\prime \prime}$ BT dan $8^{\circ} 05^{\prime}$ 8" LS dengan luas wilayah $85 \mathrm{~km}^{2}$ berupa dataran rendah yang dominan dengan penggunaan lahan persawahan, tegalan dan permukiman, seperti pada Gambar 2. 
Jurnal Pendidikan Geografi:

Kajian, Teori, dan Praktik dalam Bidang Pendidikan dan Ilmu Geografi

Volume 25, Nomor 2, Jun 2020, Hal 170-178

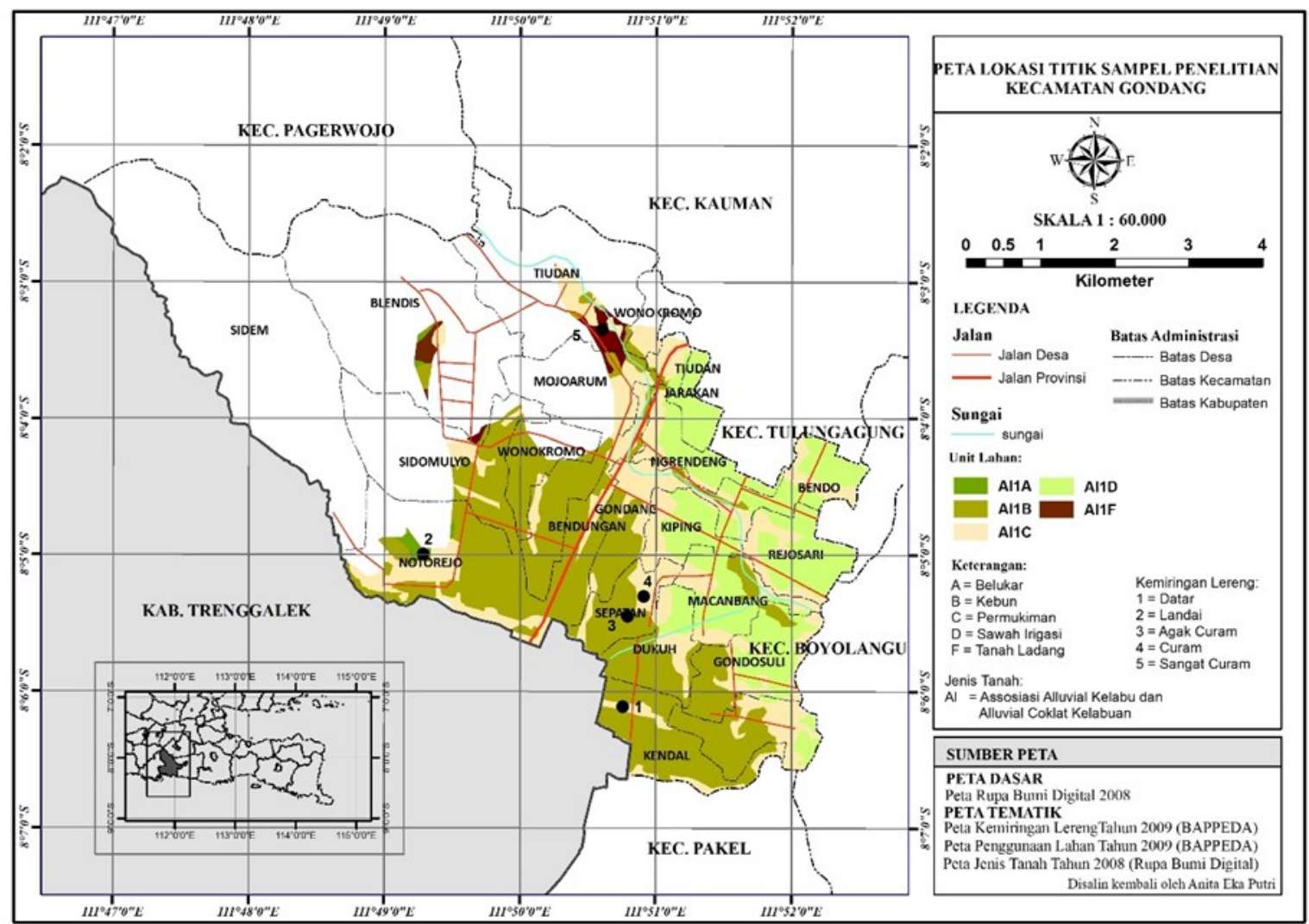

Gambar 1. Peta Pengambilan Sampel Penelitian Sumber: Analisis data 2019

Tabel 1. Titik Pengambilan Sampel Penelitian

\begin{tabular}{|c|c|c|c|}
\hline Unit Lahan & Penggunaan Lahan & Desa & Koordinat \\
\hline Al.1A & Belukar & Notorejo & $111^{\circ} 49^{\prime} 30^{\prime \prime}$ BT dan $8^{\circ} 5^{\prime} 4^{\prime \prime}$ LS \\
\hline Al.1B & Kebun & Kendal & $111^{\circ} 50^{\prime} 29,4^{\prime \prime}$ BT dan $8^{\circ} 6^{\prime} 5^{\prime}, \mathrm{LS}$ \\
\hline Al. $1 \mathrm{C}$ & Permukiman & Sepatan & $111^{\circ} 50^{\prime} 52,2^{\prime \prime}$ BT dan $8^{\circ} 5^{\prime} 22^{\prime \prime} \mathrm{LS}$ \\
\hline Al.1D & Sawah Irigasi & Sepatan & $111^{\circ} 49^{\prime} 30^{\prime \prime}$ BT dan $8^{\circ} 5^{\prime} 4^{\prime \prime}$ LS \\
\hline Al.1F & Tanah Ladang & Tiudan & $111^{\circ} 50^{\prime} 46^{\prime \prime}$ BT dan $8^{\circ} 02^{\prime} 48,7^{\prime \prime} \mathrm{LS}$ \\
\hline
\end{tabular}

Sumber: pengolahan data primer 2012, revisi 2019

Hasil pengukuran pada 5 titik sampel unit lahan masing-masing memiliki kemiringan lereng $<2 \%$ yang termasuk ke dalam kategori datar. Kawasan permukiman yang baik menurut PERMEN PU No. 41/PRT/M/2007 terletak pada kemiringan lereng yang datar sampai dengan bergelombang dengan prosentase 0-25\% (Permana, Suprayogi, \& Prasetyo, 2017), sehingga dapat disimpulkan bahwa berdasarkan tingkat kemiringan lereng di Kecamatan Gondang Kabupaten Tulungagung baik digunakan untuk permukiman. 
Jurnal Pendidikan Geografi:

Kajian, Teori, dan Praktik dalam Bidang Pendidikan dan Ilmu Geografi

Volume 25, Nomor 2, Jun 2020, Hal 170-178

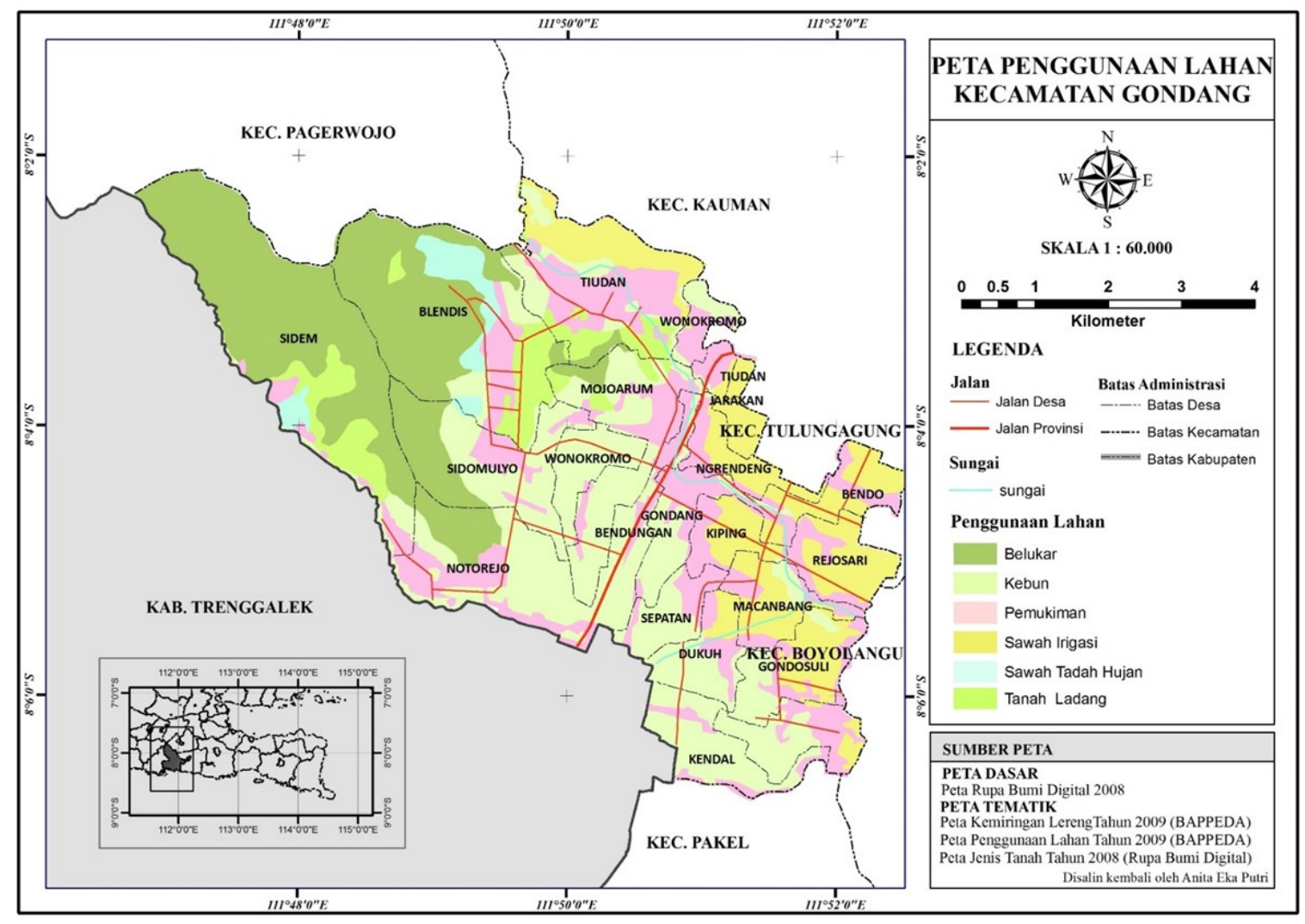

Gambar 2. Peta Penggunaan Lahan di Kecamatan Gondang Kabupaten Tulungagung Sumber: analisis data 2019

Tabel 2. Rekapitulasi Karakteristik Satuan Lahan Daerah Penelitian

\begin{tabular}{|c|c|c|c|c|c|c|c|c|c|c|}
\hline $\begin{array}{l}\text { Unit } \\
\text { La- } \\
\text { han }\end{array}$ & $\begin{array}{c}\text { Kemiri } \\
\text { ngan } \\
\text { lereng }\end{array}$ & $\begin{array}{c}\text { Kedala } \\
\text { man } \\
\text { air } \\
\text { tanah } \\
(\mathrm{m}) \\
\end{array}$ & $\begin{array}{c}\text { Tingkat } \\
\text { peng- } \\
\text { genangan/ } \\
\text { banjir }\end{array}$ & $\begin{array}{l}\text { Drain- } \\
\text { ase }\end{array}$ & $\begin{array}{l}\text { Tingkat } \\
\text { pelapukan } \\
\text { batuan }\end{array}$ & Tekstur & Struktur & $\begin{array}{l}\text { Perme- } \\
\text { abilitas }\end{array}$ & $\begin{array}{c}\text { Daya } \\
\text { dukung }\end{array}$ & $\begin{array}{l}\text { Kem- } \\
\text { bang } \\
\text { kerut }\end{array}$ \\
\hline $\begin{array}{c}\mathrm{Al} .1 \\
\mathrm{~A}\end{array}$ & Datar & $<7$ & $\begin{array}{l}\text { Tergenang } \\
2-6 \text { bulan/ } \\
\text { tahun }\end{array}$ & Jelek & $\begin{array}{c}\text { Lapuk } \\
\text { sempurna }\end{array}$ & $\begin{array}{l}\text { Lempun } \\
\text { g ber- } \\
\text { pasir }\end{array}$ & $\begin{array}{c}\text { Gumpal } \\
\text { membu- } \\
\text { lat }\end{array}$ & 0.6 & $\begin{array}{c}\text { Sangat } \\
\text { baik }\end{array}$ & 0.03 \\
\hline $\begin{array}{c}\mathrm{Al} .1 \\
\mathrm{~B}\end{array}$ & Datar & $<7$ & $\begin{array}{l}\text { Tidak } \\
\text { pernah } \\
\text { banjir }\end{array}$ & Jelek & $\begin{array}{c}\text { Lapuk } \\
\text { sempurna }\end{array}$ & $\begin{array}{l}\text { Lempun } \\
\text { g berliat }\end{array}$ & $\begin{array}{c}\text { Gumpal } \\
\text { membu- } \\
\text { lat }\end{array}$ & 0.3 & $\begin{array}{c}\text { Sangat } \\
\text { baik }\end{array}$ & 0.11 \\
\hline $\begin{array}{c}\mathrm{Al} .1 \\
\mathrm{C}\end{array}$ & Datar & $<7$ & $\begin{array}{l}\text { Tidak } \\
\text { pernah } \\
\text { banjir }\end{array}$ & Jelek & $\begin{array}{c}\text { Lapuk } \\
\text { sempurna }\end{array}$ & $\begin{array}{l}\text { Lempun } \\
\text { g ber- } \\
\text { pasir }\end{array}$ & $\begin{array}{c}\text { Gumpal } \\
\text { membu- } \\
\text { lat }\end{array}$ & 12.9 & $\begin{array}{c}\text { Sangat } \\
\text { baik }\end{array}$ & 0.03 \\
\hline $\begin{array}{c}\text { Al.1 } \\
\text { D }\end{array}$ & Datar & $<7$ & $\begin{array}{l}\text { Tidak } \\
\text { pernah } \\
\text { banjir }\end{array}$ & Jelek & $\begin{array}{c}\text { Lapuk } \\
\text { sempurna }\end{array}$ & $\begin{array}{c}\text { Liat } \\
\text { berdebu }\end{array}$ & $\begin{array}{c}\text { Gumpal } \\
\text { membu- } \\
\text { lat }\end{array}$ & 57.6 & $\begin{array}{c}\text { Sangat } \\
\text { baik }\end{array}$ & 0.11 \\
\hline$\underset{\mathrm{F}}{\mathrm{Al} .1}$ & Datar & $<7$ & $\begin{array}{c}\text { Tidak } \\
\text { pernah } \\
\text { banjir }\end{array}$ & Jelek & $\begin{array}{c}\text { Lapuk } \\
\text { sempurna }\end{array}$ & liat & $\begin{array}{c}\text { Gumpal } \\
\text { membu- } \\
\text { lat }\end{array}$ & 0.5 & $\begin{array}{c}\text { Sangat } \\
\text { baik }\end{array}$ & 0.11 \\
\hline
\end{tabular}

Sumber: Hasil penelitian, 2019 
Jurnal Pendidikan Geografi:

Kajian, Teori, dan Praktik dalam Bidang Pendidikan dan Ilmu Geografi

Volume 25, Nomor 2, Jun 2020, Hal 170-178

Muka air tanah pada sampel penelitian memiliki kedalaman muka air tanah $<7$ meter dengan kriteria kelas sangat jelek dan potensi genangan yang terlihat dari warna tanah yang semakin terang menunjukan intensitas sering tergenang, hasil pengamatan menunjukan warna tanah berada pada klasifikasi sedang dan sangat baik, drainase daerah ini yang terlihat dari bercak kuning, kelabu dan cokelat pada profile tanah tergolong dalam klasifikasi jelek.

Dilihat dari aspek di atas daerah tersebut memiliki potensi terjadi genangan banjir karena muka air tanah dan drainase yang kurang bagus akan tetapi tidak sering tergenang dilihat dari warna tanahnya. Tingkat pelapukan di lokasi penelitian berada dalam klasifikasi jelek, berbeda dengan tekstur tanah yang relatif beragam dalam klasifikasi jelek, sedang dan baik. Pelapukan dan tekstur tanah akan menentukan kualitas pondasi bangunan.

Permeabilitas tanah atau hasil uji komposisi lempung, debu dan pasir berdasarkan hasil uji laboratorium berada pada klasifkasi jelek. Begitupun dengan daya dukung tanah berada dalam klasifikasi sangat jelek, namun potensi kembang kerut tanah yang berpengaruh pada kualitas bangunan berada pada klasifikasi baik dan sangat jelek.

Semakin tinggi index cole dapat menyebabkan potensi tembok mudah retak, dan mengalami lembab karena pada saat musim penghujan akan mudah mengembang dan mengkerut pada saat musim kemarau. Keadaan seperti ini akan mempengaruhi keawetan suatu bangunan.Rekapitulasi klasifikasi penelitian seperti pada Tabel 2.

Kesesuaian lahan untuk permukiman diklasifikasikan dalam 5 kelas, yaitu sangat sesuai $\left(\mathrm{S}_{1}\right)$, cukup sesuai $\left(\mathrm{S}_{2}\right)$, Sesuai Marginal $\left(\mathrm{S}_{3}\right)$, tidak sesuai saat ini $\left(\mathrm{N}_{1}\right)$, dan tidak sesuai permanen $\left(\mathrm{N}_{2}\right)$. Berdasarkan interval hasil penelitian tersebut ditentukan kelas kesesuaian lahan seperti pada Tabel 3.

Berdasarkan karakteristik lahan yang didasarkan pada kemiringan lereng, kedalaman muka air tanah, tingkat penggenangan/banjir, drainase, tingkat pelapukan batuan, tekstur, struktur, permeabilitas, daya dukung, dan kembang kerut (index cole) diperoleh kelas kesesuaian lahan Sesuai Marginal $\left(\mathrm{S}_{3}\right)$ untuk semua unit lahan di Kecamatan Gondang Kabupaten Tulungagung. Utuk persebaran dan luasannya dapat dilihat pada Gambar 3 dan Tabel 4.

Tabel 3 Kelas KesesuaianLahan Untuk Permukiman

\begin{tabular}{|c|c|c|c|}
\hline Kelas & Kesesuaian lahan & $\begin{array}{l}\text { Jumlah } \\
\text { harkat }\end{array}$ & Kriteria \\
\hline I & $\begin{array}{c}\text { Sangat } \\
\text { Sesuai }\left(\mathrm{S}_{1}\right)\end{array}$ & $99-115$ & $\begin{array}{l}\text { Satuan lahan dengan kondisi sangat sesuai untuk permukiman, tidak } \\
\text { mempunyai faktor pembatas yang berat, atau hanya mempunyai faktor } \\
\text { pembatas yang kurang berarti dan tidak terpegaruh secara nyata } \\
\text { terhadap penggunaan lahan }\end{array}$ \\
\hline II & $\begin{array}{l}\text { Cukup } \\
\text { Sesuai }\left(\mathrm{S}_{2}\right)\end{array}$ & $80-98$ & $\begin{array}{l}\text { Satuan lahan dengan kondisi cukup sesuai untuk permukiman dengan } \\
\text { sedikit faktor pembatas agak berat }\end{array}$ \\
\hline III & $\begin{array}{l}\text { Sesuai Marginal } \\
\qquad\left(\mathrm{S}_{3}\right)\end{array}$ & $61-79$ & $\begin{array}{l}\text { Satuan lahan dengan faktor pembatas yang sangat berat apabila } \\
\text { dipergunakan sebagai kawasan permukiman }\end{array}$ \\
\hline IV & $\begin{array}{l}\text { Tidak Sesuai Saat } \\
\operatorname{Ini}\left(\mathrm{N}_{1}\right)\end{array}$ & $42-60$ & $\begin{array}{l}\text { Satuan lahan dengan faktor pembatas yang sangat berat tetapi masih } \\
\text { memungkinkan untuk diatasi, hanya saja tidak dapat diperbaiki dengan } \\
\text { tingkat pengetahuan saat ini dengan biaya rasional }\end{array}$ \\
\hline V & $\begin{array}{l}\text { Tidak Sesuai } \\
\text { Permanen }\left(\mathrm{N}_{2}\right)\end{array}$ & $23-41$ & $\begin{array}{l}\text { Satuan lahan dengan kondisi tidak sesuai untuk permukiman karena } \\
\text { mempunyai faktor pembatas yang sangat berat }\end{array}$ \\
\hline
\end{tabular}

Sumber: Hasil analisis revisi 2019 
Jurnal Pendidikan Geografi:

Kajian, Teori, dan Praktik dalam Bidang Pendidikan dan Ilmu Geografi

Volume 25, Nomor 2, Jun 2020, Hal 170-178

Tabel 4. Luas Kesesuaian Lahan Sesuai Marginal $\left(\mathrm{S}_{3}\right)$ di Kecamatan Gondang

\begin{tabular}{|c|c|c|c|c|}
\hline No. & Unit Lahan & Penggunaan Lahan & Luas (Ha) & Presentase \\
\hline 1. & Al.1A & Belukar & 10,82 & 0,52 \\
\hline 2. & Al.1B & Kebun & 917,81 & 47,08 \\
\hline 3. & Al.1C & Permukiman & 584,36 & 28,14 \\
\hline 4. & Al.1D & Sawah Irigasi & 535,91 & 25,81 \\
\hline 5. & Al.1F & Ladang & 27,59 & 1,32 \\
\hline \multicolumn{3}{|c|}{ Jumlah } & 2076,49 & $100 \%$ \\
\hline
\end{tabular}

Sumber: Data analisis 2019

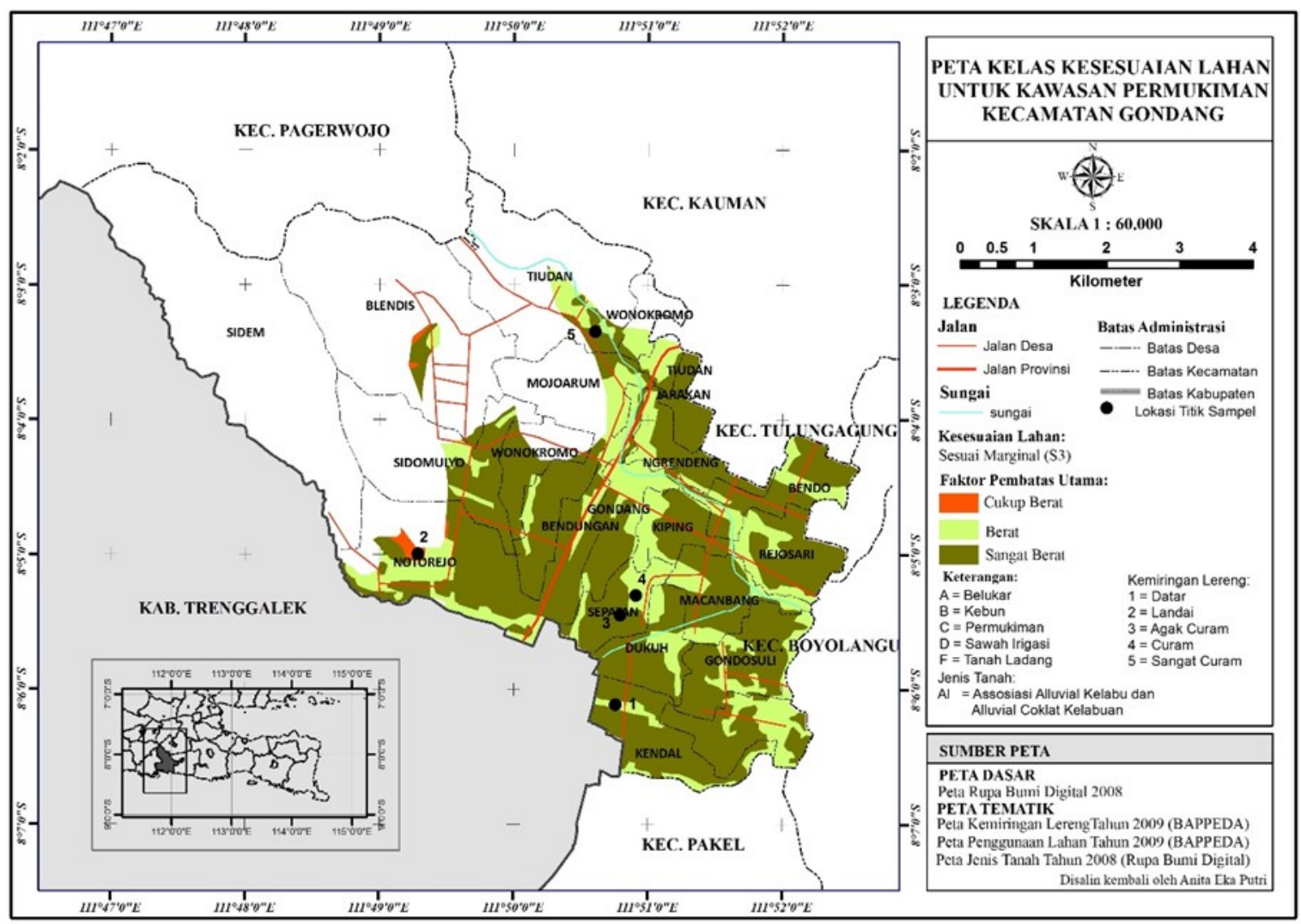

Gambar 3 Peta Kelas Kesesuaian Lahan untuk Permukiman di Kecamatan Gondang Sumber: Analisis data 2019

Kelas kesesuaian lahan Sesuai Marginal $\left(\mathrm{S}_{3}\right)$ diperuntukkan hampir pada semua jenis unit lahan, hanya yang membedakannya adalah jumlah faktor pembatas. Adapun luasan untuk kelas Sesuai Marginal pada jenis penggunaan lahan kebun adalah 917,81 $\mathrm{Ha}$, belukar 10,82 Ha, sawah irigasi 535,91 Ha, Tanah lading 27,59 Ha dan permukiman 584,36 Ha dengan jumlah keseluruhan luas lahan 2.076,49 Ha.

Sub kelas kesesuaian lahan Sesuai Marginal $\left(\mathrm{S}_{3}\right)$ mempunyai faktor pembatas berat apabila dijadikan sebagai kawasan permukiman. Namun hal itu masih dapat diatasi dengan tingkat pengetahuan konstruksi bangunan dan membutuhkan biaya tambahan untuk menghasilkan bangunan kualitas baik. 
Jurnal Pendidikan Geografi:

Kajian, Teori, dan Praktik dalam Bidang Pendidikan dan Ilmu Geografi

Volume 25, Nomor 2, Jun 2020, Hal 170-178

\section{KESIMPULAN}

Karakteristik lahan daerah bekas rawa di Kecamatan Gondang Kabupaten Tulungagung berada pada kemiringan lereng datar, mempunyai kedalaman muka air tanah $<7$ meter dari permukaan tanah, tidak tergenang sepanjang tahun, mempunyai drainase jelek, tingkat pelapukan batuan sempurna dan hampir di setiap unit lahan mempunyai kandungan monmorinit sangat tinggi sehingga kemampuan kembang kerut tanah (index cole) tinggi. Kelas kesesuaian lahan daerah bekas rawa di Kecamatan Gondang untuk pengembangan kawasan permukiman termasuk ke dalam kelas Sesuai Marginal (S3) di mana kondisi lahan memiliki beberapa faktor pembatas yang sangat berat sehingga apabila dikembangkan sebagai kawasan permukiman perlu adanya penanganan dan tindak lanjut, seperti pembuatan pondasi bangunan harus lebih kuat, memperhatikan kualitas material yang baik agar bangunan mempunyai kualitas yang baik dan awet dalam jangka panjang.

\section{DAFTAR RUJUKAN}

Alfianto, F. (2017). Analisa kesesuaian lahan untuk lokasi pengembangan permukiman menggunakan metode skoring (studi kasus: Surabaya Timur). Jurnal Geomatika.

Arsyad, S. (2006). Konservasi tanah dan air . Bogor: IPB Press.

Asmirawati. (2015). Kesesuaian lahan pengembangan perkotaan Kajang Kabuaten Bulukumba. Jurnal Teknik Universitas Negeri Makassar.

Bappekab, T. (2006). Rencana tata ruang wilayah Kabupaten Tulungagung 2006-2016. Tulungagung: Pemkab Tulungagung.

Bappekab, T. (2010). Rencana tata ruang wilayah Kabupaten Tulungagung 2009-2030. Tulungagung: Pemkab Tulungagung.

Bappekab, T. (2019). Kabupaten Tulungagung dalam angka. Tulungagung: Pemkab Tulungagung.

Dewi, I. K. (2017, Maret 20). Evaluasi kerawanan bencana tanah longsor di kawasan permukiman di Daerah Aliran Sungai (DAS) Ciliwung Hulu. Jurnal Prodi PWK Fakultas Teknik Universitas Pakuwan.

Forth, H. D. (1988). Dasar-dasar ilmu tanah. Yogyakarta: UGM Press.

Hartono, Anggoro, S., \& Buchori, I. (2015, April ). Evaluasi kesesuaian lahan permukiman Perum Bakti Persada Indah Kelurahan Purwoyoso Semarang. Jurnal Teknis, 10, 22-30.

Hilmansyah, H., \& Rudianto, I. (2015). Kajian perkembangan dan kesesuaian lahan permukiman eksisting di Kecamatan Indramayu. Jurnal Teknik Pengembangan Wilayah Kota, 4, 54-65.

Mufarikah , N. N., \& Murti, S. H. (2015). Evaluasi perkembangan lahan permukiman berbasis penginderaan jauh dan sistem informasi geografis di Kota Magelang dan sekitarnya tahun 2015. Jurnal Pendidikan Geografi.

Permana, D. P., Suprayogi, A., \& Prasetyo, Y. (2017). Identifikasi kesesuaian lahan untuk relokasi permukiman menggunakan sistem informasi geografis (studi kasus: Kabupaten Banjarnegara). Jurnal Geodesi UNDIP, 6.

Putra, R. A., \& Papilaya , S. F. (2019, Januari). Evaluasi kesesuaian lahan permukiman terhadap tata ruang wilayah di Salatiga. Jurnal Sistem Informasi Fakultas Teknologi Infomasi.

Susetya, B., Widyatmaka, \& Arifin, H. S. (2014, Juni ). Analisis spasial kemampuan dan kesesuaian lahan untuk mendukung model perumusan kebijakan manajemen lanskap di Sempadan Ciliwung Kota Bogor. Jurnal Majalah Ilmiah Globe, 16. 
Jurnal Pendidikan Geografi:

Kajian, Teori, dan Praktik dalam Bidang Pendidikan dan Ilmu Geografi

Volume 25, Nomor 2, Jun 2020, Hal 170-178

Ulah, K. M., \& Mansourian, A. (2015). Evaluation of Land Suitability for Urban LandUse Planning: Case Study Dhaka City. Journal of Physical Geography and Ecosistem Science.

Umar, I., Widiatmaka, Pramudya, B., \& Barus, B. (2017, Agustus ). Evaluasi Kesesuaian Lahan Untuk Kawasan Permukiman Dengan Metode Multi Criteria Evaluation Di Kota Padang. Jurnal Pengelolaan Sumber Daya Alam dan Lingkungan, 7 (2), 148154.

Veni. (2016). Evaluasi Lahan Untuk Permukiman di Kanagarian Painan Kecamatan IV Jurai Kabupaten Pesisir Selatan. Jurnal Kepemimpinan dan Pengurusan Sekolah, 1.

Yunus, I. (2014, Agustus ). Tata Pengelolaan Banjir Pada Daerah Reklamasi Rawa (Studi Kasus: Kawasan Jakabaring Kota Palembang). PIT HATHI, 22-24. 